\title{
DEVELOPMENT AND TESTING OF A RISK INDEXING FRAMEWORK TO DETERMINE FIELD-SCALE CRITICAL SOURCE AREAS OF FAECAL BACTERIA ON GRASSLAND
}

\author{
David M. Oliver ${ }^{1 *}$, Trevor Page ${ }^{1}$, Chris J. Hodgson ${ }^{2}$, A. Louise \\ Heathwaite $^{1}$, Dave R. Chadwick ${ }^{2}$, Rob D. Fish ${ }^{3}$ and Michael Winter ${ }^{3}$ \\ 1 Centre for Sustainable Water Management, Lancaster Environment Centre, Lancaster University, \\ Lancaster, UK, LA1 4AP \\ 2 North Wyke Research, Okehampton, Devon, UK, EX20 2SB \\ 3 Centre for Rural Policy Research, Department of Politics, University of Exeter, Exeter, \\ Devon, EX4 6TL
}

*Corresponding author: David M. Oliver (d.m.oliver@lancaster.ac.uk). Tel: +44 (0)1524 510231, Fax: +44 (0)1524 510217. Centre for Sustainable Water Management, Lancaster Environment Centre, Lancaster University, Lancaster, LA1 4AP, UK. 
This paper draws on lessons from a UK case study in the management of diffuse microbial pollution from grassland farm systems in the Taw catchment, south west England. We report on the development and preliminary testing of a field-scale faecal indicator organism risk indexing tool (FIORIT). This tool aims to prioritise those fields most vulnerable in terms of their risk of contributing FIOs to water. FIORIT risk indices were related to recorded microbial water quality parameters (faecal coliforms [FC] and intestinal enterococci [IE]) to provide a concurrent on-farm evaluation of the tool. There was a significant upward trend in $\log [\mathrm{FC}]$ and $\log [\mathrm{IE}]$ values with FIORIT risk score classification $\left(\mathrm{r}^{2}=0.87\right.$ and 0.70 , respectively and $\mathrm{P}<0.01$ for both FIOs). The FIORIT was then applied to 162 representative grassland fields through different seasons for ten farms in the case study catchment to determine the distribution of on-farm spatial and temporal risk. The high risk fields made up only a small proportion $(1 \%, 2 \%, 2 \%$ and $3 \%$ for winter, spring, summer and autumn, respectively) of the total number of fields assessed (and less than $10 \%$ of the total area), but the likelihood of the hydrological connection of high FIO source areas to receiving watercourses makes them a priority for mitigation efforts. The FIORIT provides a preliminary and evolving mechanism through which we can combine risk assessment with risk communication to end-users and provides a framework for prioritising future empirical research. Continued testing of FIORIT across different geographical areas under both low and high flow conditions is now needed to initiate its long term development into a robust indexing tool.

Key-words: diffuse pollution; E. coli; expert knowledge; faecal indicator organism; index; pathogens; risk; water quality

\section{INTRODUCTION}


Catchments dominated by agriculture have consistently been shown to generate high faecal indicator organism (FIO) pollutant concentrations in receiving waters (Sinclair et al., 2009; Kay et al., 2008a). Consequently, farmers and land owners are under constant pressures and legal obligations to safeguard waterbodies and protect the environment. While nutrient management planning and associated decision support and risk assessment frameworks (such as the Phosphorus index [PI]) are relatively well established (e.g. Lemunyon and Gilbert, 1993; Buczko and Kuchenbuch, 2007), no risk index tool exists to identify the relative risk of farmed land in contributing microbial pollutants to water at the field scale. This is surprising given the inclusion of complementary directives such as the revised Bathing Waters Directive (rBWD) (CEC, 2006) within the WFD in Europe (CEC, 2000), microbial contaminants being a leading cause of impairment of U.S. waterbodies (USEPA 2009), and that convenient non-pathogenic microbial parameters, known as faecal indicator organisms (FIOs), can be used as surrogate measures of infection risk to humans throughout the world (Kay et al., 2007).

Contamination of watercourses with agriculturally-derived FIOs can occur through (i) direct routes such as animal access and defecation into streams; and via (ii) rainfall-driven transfer from farm systems to water through surface and subsurface hydrological pathways (Oliver et al., 2005). An increased potential for the delivery of FIOs from agricultural land to water can be linked to 'ill-timed' manure spreading activity and poor farm management such as excessive manure application rates and spreading on frozen ground (Chadwick et al., 2008). Once excreted from livestock, FIOs are not well adapted to survive in the farm environment and their numbers decline as a function of environmental variables (Sinton et al., 2007). However, variability in FIO die-off is such that there will often exist a period of increased risk for FIOs to be mobilised from a manure or directly excreted source, transferred through farmed land and potentially delivered to a receiving water while still in sufficient numbers to cause problems downstream and in coastal waters (Wilkinson et al., 2006). There is an expanding (though immature relative to $\mathrm{P}$ and $\mathrm{N}$ ) body of empirical FIO-related science which can form the 'evidence base' for good regulatory 
practice (Kay et al., 2008b) and the conceptual framework outlined in this paper has been designed around the findings of existing research.

Efforts have been made to develop process-based deterministic catchment scale pathogen models, or budgets, through inclusion of land-based inputs, hydrological routing modules and GIS data layers (e.g. Ferguson et al., 2005, 2007). In contrast, Goss and Richards (2008) have argued that development of a risk-based index of the potential for pathogens from agricultural activity to impact on water quality is required as an interim stage in the establishment of a fully quantitative microbial risk assessment approach. The aim of this study was therefore to: (i) use established risk factors (RFs) within the current evidence base to develop a conceptual framework for an FIO risk indexing tool that allows land managers to follow a procedure for logical risk assessment of relative FIO loss from land to water on a field-by-field basis; (ii) assess the spatial and temporal distribution of risk indices ; and (iii) provide a preliminary assessment of the reliability of FIORIT on farm fields using the Taw catchment in Devon, southwest England, as a case study to demonstrate the practical application of the index.

\section{METHODS}

\section{Conceptual Basis for the FIO Risk Indexing Tool}

The basic premise of the conceptual framework for FIORIT was that FIO related pollution is derived from critical source areas (CSAs). By this we mean that source (availability) and transfer (mobilisation) factors must be combined and then coupled with connectivity (likelihood of delivery) for a potential risk to become an actual risk. We have adopted and modified a framework similar to that proposed by Heathwaite et al. (2000) during the development of a phosphorus assessment tool. The risk indexing approach is intended to identify fields where the potential risk of FIO loss from land to water may be higher or lower relative to other spatial locations in a farm boundary and across different seasons. Seasons (for the northern hemisphere) were defined as: winter [December through February], spring [March through May], summer [June through August] and autumn [September through November]. 
Key transport, source and connectivity drivers thought to influence FIO loss from land to water are outlined in a preliminary risk framework (Tables 1 and 2). While the rationale for inclusion of the RFs within each of the risk criteria is based on current empirical research, ascertaining their relative importance when operating simultaneously at the farm scale is beyond the remit of most specific research projects. In order for us to make some working assessments of how factors embedded in these risk criteria could be assigned significance, we initiated a process of expert consultation (c.f. Simsek and Veiga, 2000). Thus, existing data and research cited in this paper (Table 1) formed the crux of the framework and expert judgement configured the relative importance of the RFs.

\section{Expert Weighting Approach}

This approach made use of an expert consortium comprising 16 members. Full details of the expert elicitation approach are documented in Fish et al. (2009). Briefly, members were selected on the basis of their research history, international standing and expertise in their field to ensure FIORIT was robust across a range of cognate scientific areas (c.f. Cornelissen et al., 2003). The weightings reflect the current perceptual understanding of microbiologists, soil and contaminant scientists, manure management experts, policy makers and geographers. The weighting for each RF varied on a continuous scale ranging from 0 (of no importance) through to 1 (of absolute importance). Experts were requested to leave their score blank for any RFs that they felt unable to weight with confidence. This process was not intended to generate an extensive sample of views. Rather, it developed indicative responses from relevant disciplines that could help make our risk tool operational. The sensitivities and uncertainties associated with the expert weightings were explored in preliminary analyses.

\section{Description of the FIO Risk Indexing Tool}

The framework for the risk indexing tool was designed to use readily accessible field data, farmer knowledge and nationally available GIS databases (digital terrain models and digitised survey 
maps: see Table 1). The FIORIT used parameters that have an influence on FIO availability (source), transfer and rapid connectivity to a watercourse (Table 1). It is recognised that a wide range of parameters could have been incorporated but the index was designed to be parsimonious and to include only key RFs whose contribution could be justified (by the existing empirical evidence-base). A detailed rationale for the inclusion of each RF is also available (CSWM, 2009). Because little empirical work has been undertaken to evaluate the role of mitigation and management practices to reduce FIO loss at the field scale we were unable to justify the inclusion of risk-reducing factors within the FIORIT framework at this time. However, the conceptual framework is in a form such that future refinements are both encouraged and simple to implement.

\section{Generating Risk Indices}

To determine the in-field impact of each of the RFs identified in Table 1, the user must multiply the RF Weighting (wtg) by the relative risk associated with the magnitude of each factor (RM):

$$
\text { RF score }=w \operatorname{tg} \times R M
$$

The potential risk associated with each field was then calculated using the following procedure:

(i) A field assessor, via a farm audit and detailed farmer survey, was required to rate the RM of each RF from 'negligible' through to 'very high' risk based on a pre-determined definition of each risk category (see Table 2). This defined framework, linked to a series of databases and data collection methods (Table 1) was a means of standardising a subjective exercise into a more robust and replicable protocol. The corresponding score linked to each RM was established manually using a series of scenarios (Table 3) rather than automatic optimisation to avoid over constraint on sparse and uncertain data. .

(ii) The RM was then multiplied by the RF weighting to obtain the score associated with each individual RF (see Equation 1). 
(iii) The resulting RF score obtained by Equation 1 was summed for each risk criteria (i.e.. $\Sigma$ source RFs, $\Sigma$ transfer RFs, $\Sigma$ connectivity RFs).

(iv) The FIO risk index $\left(\mathrm{FIO}_{\mathrm{RI}}\right)$ for each field was then obtained by Equation 2:

$F I O_{R I}=\left(\sum\right.$ sourceRFs $) \times\left(\sum\right.$ transferRFs $) \times\left(\sum\right.$ connectivityRFs $)$

The framework was specifically designed in a multiplicative rather than additive fashion to ensure that field vulnerability was best represented. For example, if transfer potential within a field was negligible, its vulnerability would be low, regardless of manure applications or grazing activity (c.f. Heathwaite et al., 2000).

(v) The resultant score is arbitrary but provides a normalised scale upon which to assign relative potential risk to each assessed field. Based on typical output from a range of farms, risk categories were broken down into five classes of: $0=$ negligible (but crucially not zero risk); 1-100 = low-; 101-200 = medium-; 201-300 = high-; and > 300 = very high- risk). Temporal and spatial changes in relative potential risk can then be communicated visually in a map format to the end-user by georeferencing risk indices into a GIS (c.f. Defra 2005a).

(vi) Although negligible risk fields were indexed as 0, this did not imply that the field would be 'risk free' but that the observed criteria suggested a negligible potential risk attributed to a field. Furthermore, no fields were considered to be completely devoid of hydrological connectivity because slow pathways through the soil matrix were likely to operate when more direct routes of hydrological connectivity were absent. To account for this, those fields that did not register a score for connectivity RFs within FIORIT were assigned a connectivity coefficient of 0.1 for multiplication with source and transfer related risk drivers. This ensured that an appreciation of slower delivery mechanisms remained within the indexing approach, though operating at a much reduced magnitude due to the filtering capabilities of the soil matrix and in line with our conceptual understanding of FIO loss from land to water. 


\section{A case study from the Taw catchment, Devon}

The Taw Catchment in Devon, UK is presented as a case study to contextualise the FIORIT and demonstrate its practical application on agricultural land. The Taw catchment is $1200 \mathrm{~km}^{2}$ in area and typifies a major European catchment type with intensive livestock production on rural grassland which accounts for $>80 \%$ of the land use. The soils are moderately permeable and are coupled with low groundwater storage resulting in rapid stream responses to rainfall and a catchment hydrology dominated by near-surface runoff and rapid hydrograph recession (Jarvie et al., 2008). A sample of 162 grassland fields across 10 farms in the Taw catchment were assessed using the FIORIT in order to derive a first-approximation of risk indices for winter, spring, summer, and autumn scenarios and thus assess the distribution of spatial and temporal on-farm risk within the geographic constraints on the case study area. To demonstrate potential development and testing of FIORIT we have included an evaluation of microbial water quality data (collected at two of the 10 farms) against output from FIORIT and also included a set of risk indices linked to FIORIT modified with a rainfall likelihood coefficient (RLC) derived from 30 year average rainfall records for the Taw catchment (Morris, 1999). The RLC served to scale risk indices relative to seasonal rainfall, working from the assumption that rainfall forms a crucial driver of FIO mobilisation from land and delivery to water (Oliver et al., 2005a). Thus, 'winter' (highest rainfall) was normalised to an RLC of 1.0 (Taw catchment long term average monthly rainfall of $121 \mathrm{~mm}$ ) and all other seasons were graded to derive RLC's of $0.99,0.65$ and 0.63 for autumn, spring, and summer, respectively, in proportion to their relatively lower average rainfall totals of $112 \mathrm{~mm}, 78 \mathrm{~mm}$, and $76 \mathrm{~mm}$. Such seasonal coefficients are spatially sensitive and can be derived for any study area of the UK using this nationally available dataset. Elsewhere, equivalent nationally available long-term rainfall records can be used.

\section{Farm and Field Description}

Microbial water quality data were collected from monitoring sites located on two of the ten farms (see Fig 2 and Table 4 for field details) in the Taw catchment. The two farms differed in their physical layout and general management, but were situated within close proximity to one another 
with similar climatic conditions. Briefly, the mean temperature for winter, spring, summer and autumn (at both field sites) was 5.0, 8.3, 16.3, and $12.5^{\circ} \mathrm{C}$, respectively. October was the wettest month with $151 \mathrm{~mm}$ of rainfall and July the driest with $26 \mathrm{~mm}$ rainfall. In January 2006 only one quarter of the typical average monthly rainfall was recorded. During 2006, annual rainfall for the south west of England was 1129 mm (Met Office, 2007), 7\% lower than the 1961-1990 long term average. Farm A was 120 ha in size and held 35 beef cows, 35 calves and 1150 sheep. Farm B was 117 ha and stocked with 72 beef cattle and 1072 sheep. Both farms were predominantly grassland (87\% and 69\% of total land area for Farm A and B, respectively). On-farm verification of a field scale tool is difficult to achieve at the un-replicated farm scale due to inherent uncertainties associated with FIO sources and pathways within farm systems. Subsequently, the focus of the evaluation study was four contrasting seasons of management for two key contributory grassland fields adjacent to the watercourse (one within each of the farm boundaries; Field 1 on Farm A and Field 2 on Farm B). The two fields were chosen based on comprehensive farm survey and assessment exercises, farmer knowledge, and through preliminary risk screening. The aim was to minimise external FIO inputs from neighbouring farmed land due to favourable surrounding land-use (woodland) and site location. A stream monitoring site at each field boundary was set up and samples collected during a 12-month period, allowing for estimates of typical seasonal flux $\left(\mathrm{CFU} \mathrm{L} \mathrm{s}^{-1}\right)$ for the year 2006. In the case of these two farms, no small feeder streams intercepted the sample site, thus minimizing contributions of FIOs from other fields. For Farm B, water quality was measured at an upstream location before it entered Field 2 and FIO inputs were consistently negligible. Furthermore, the field assessed on Farm B was situated on both sides of the stream negating the problematic role of extraneous inputs from a field on the opposite stream bank. Field 1 on Farm A was in close proximity to the stream source and so limited input was considered to be attributed from above the farm and this was confirmed by upstream analysis. Additionally, the stream was surrounded on the opposite bank with riparian woodland. We therefore judged that the two key fields we assessed for FIO loss vulnerability must be considered the dominant contributors to the microbial water quality of the sample site. 


\section{Instrumentation}

Stream discharge $(\mathrm{Q})$ measurements were completed at each farm to obtain FIO flux data. Stream Q was estimated using the area-velocity method (Fetter, 2001). Flow velocity was measured using a Valeport model 002 open channel flow meter (Valeport Ltd., UK). Cross sectional area of the stream as a function of water level was determined and a rating equation derived to describe the stage-discharge relationship. Precipitation data was collected at farm sites using a Skye Minimet meteorological station (Skye Instruments Ltd., UK).

\section{Sample Collection and Analysis}

Both faecal coliforms (FC) and intestinal enterococci (IE) were recorded to provide a comparative evaluation of FIORIT against two routine FIOs. Regular fortnightly grab sampling over one year was augmented with a more intensive sampling campaign during key periods of the year thought to be associated with high risk of FIO delivery to water. Water samples were collected in presterilised 500-mL, screw top polypropylene bottles, stored on ice in a cool box and analyzed in the laboratory within $6 \mathrm{hr}$ of collection. During the more intensive sampling campaign for each farm, a mobile laboratory was utilised to aid timely plating of the samples. On these occasions the time between collection of the water sample and laboratory analysis was 2 to $4 \mathrm{hr}$. All stream samples were analyzed for presumptive FC, and presumptive IE using standard UK methods based on membrane filtration (Anon, 2002).

\section{Statistical Analysis}

Microbial data were log-transformed and statistical analysis was performed using these transformed data using Genstat 9.1 for Windows (VSN International, 2006). Instantaneous microbial flux (c.f. Oliver et al., 2005a) was calculated by multiplying discharge by concentration. Comparisons of farm data (both flow and microbial) were made using a two-tailed $t$ test. Pearson's product-moment correlation coefficients were derived to assess the association between microbiological variables and risk indices. Linear regression was used to discriminate the 
percentage of variance in FIO flux explained by FIORIT. Other regression models, including quadratic, were evaluated but did not provide significant improvement in the linear model.

\section{RESULTS}

\section{Expert weightings and associated sensitivity and uncertainty analyses}

The expert weighted data provided information on the importance of RFs relative to one another.. The mean values are shown within the matrix framework (Table 2). The average from the return of 16 weightings was accommodated within the risk index as the final weighting per RF so as not to desensitise upper and lower expert weightings. This was because experts only weighted RFs if they were confident in their judgements, and so it was inappropriate to use the median. The ranges of the expert weightings are published elsewhere (Fish et al., 2009).

The form of the FIORIT equation (Eqn. 2) is such that there are 3, 7 and 6 variables associated with the transport, source and connectivity risk criteria, respectively. This means that these criteria have relative implicit weightings of $1,0.43$ and 0.5 , respectively. The actual sensitivity of the expert weightings is however dependent upon the magnitude of the expert weighting in question, the magnitudes of the other expert weightings in each class and the magnitudes of the risk scores in each class for any given field as shown in Equation 3. For example, for any given field if the $\mathrm{RM}=0$ then the risk factor will be insensitive by definition.

$$
S I_{w t g_{i}}=\frac{F I O_{R I} \times\left(1+(k-1) \times \frac{w t g_{i} \times R M_{i}}{\sum_{j=1}^{N} w t g_{j} \times R M_{j}}\right)-F I O_{R I}}{w t g_{i} \times \Delta w t g_{i}}
$$

where: $S I_{w t g}$ is the sensitivity index for a given expert weighting, $k$ is a multiplier in the sensitivity analysis which determines the change in a given expert weighting and $N$ is the number of weightings in $\mathrm{wtg}_{\mathrm{i}}$ 's class. 
RFs attributed with the highest expert weighting but which also accommodated a large range (or lack of consensus) in expert scores (see Fish et al., 2009) are implicitly the most uncertain, and vice versa. Thus, 'livestock access to streams' and 'livestock type' were identified as the most and least uncertain RFs within FIORIT. Following Livestock access to streams, the RFs contributing most error intrinsic to the index were 'overland Flow distance' and 'runoff potential'.

\section{Water Quality Data and Field Risk Indices}

There was a significant $(\mathrm{P}<0.001)$ difference in the average recorded stream flow (measured at time of microbial sample collection) at both farms. Flow at Farm A averaged $22 \mathrm{~L} \mathrm{~s}^{-1}$ compared to $50 \mathrm{~L} \mathrm{~s}^{-1}$ at Farm B. For Farm A, measured flux on sampling dates ranged between $\log _{10} 4.0$ and $\log _{10} 5.8 \mathrm{CFU} \mathrm{L} \mathrm{s}^{-1}$ for $\mathrm{FC}$, and for IE the range spanned from $\log _{10} 3.46$ to $\log _{10} 5.77 \mathrm{CFU} \mathrm{L}^{-1} \mathrm{~s}^{-1}$. On Farm B, the range in FC values was of a higher magnitude $\left(\log _{10} 5.4\right.$ to $\left.\log _{10} 7.6 \mathrm{CFU} \mathrm{L} \mathrm{L}^{-1} \mathrm{~s}^{-1}\right)$ as was that associated with IE $\left(\log _{10} 4.7\right.$ to $\left.\log _{10} 7.2 \mathrm{CFU} \mathrm{L} \mathrm{L}^{-1} \mathrm{~s}^{-1}\right)$. An example of FIO fluctuations through time and with respect to daily rainfall is shown in Figure 2. This shows measured FIO flux in time-series during 'spring' on both of the farms. The flux (and hence concentrations) of FC are consistently higher than that of IE at both Farm A and B. Neither FC nor IE flux exceeded $1 \times 10^{6} \mathrm{CFU} \mathrm{L}^{-1} \mathrm{~s}^{-1}$ on Farm A, which contrasted with CFUs exceeding this threshold on Farm B. Throughout the year, the average measured flux of FC and IE was significantly higher $(\mathrm{P}<0.0001)$ at Farm B.

The microbial water quality data enabled calibration of RM categories within FIORIT. The scenarios shown in Table 3 provided $\mathrm{r}^{2}$ values for the unmodified and RLC modified FIORIT as shown in Table 5. Thus the arithmetric progression of $0,1,2,3,4$ was adopted for RM categorisation within the FIORIT rather than a geometric progression. In turn, the FIORIT risk indices for Field 1 (Farm A) were 100 (low), 144 (medium), 112 (medium) and 197 (medium) for spring, summer, autumn and winter, respectively. When modified using the RLC, the risk indices for those same seasons converted to 65 (low), 91 (low), 111 (medium) and 197 (medium). Derived risk indices for Field 2 (Farm B) were relatively high: 291 (high), 389 (very high), 325 
(very high) and 168 (medium) for spring, summer, autumn and winter, respectively, converting to 189 (medium), 245 (high), 385 (very high) and 168 (medium) when modified with the RLC. In an attempt to provide a preliminary quantification of the potential errors in FIORIT output stemming from the uncertainty in the expert weightings, we performed an uncertainty analysis of the unmodified FIORIT risk indices (Figure 3). The uncertainty assessment took the form of a simplistic forward-propagation methodology using Monte Carlo sampling from normal distributions generated using the mean and standard deviations from the elicited expert weightings. Figure 3 shows the resulting ranges of predicted risk indices in the form of box and whisker plots. where it can be seen that on average there is approximately $+/-30 \%$ error between the $50^{\text {th }}$ and the $25^{\text {th }}$ and $75^{\text {th }}$ percentiles. Ideally this uncertainty analysis should be extended to include constraint of risk index estimates with field data (e.g. by using the GLUE method (Beven and Binley, 1992). We chose not to extend our uncertainty analysis in this case owing to limited field data available for model constraint.

There was a significant $(\mathrm{P}<0.01)$ upward trend $(\mathrm{Fig} 4 \mathrm{~A})$ in both $\log [\mathrm{FC}]$ and $\log [\mathrm{IE}]$ values with increasing risk indices derived by FIORIT using the unmodified framework. The intercept at the lowest level of risk corresponded to a greater than expected FIO flux of between 3-10 x $10^{3} \mathrm{CFU}$ $\mathrm{L}^{-1} \mathrm{~s}^{-1}$. Adapting FIORIT based on the RLC allowed us to scale down field risk indices (potential risk) associated with seasons during which rainfall is typically less likely. Evaluation of the relationship between microbial water quality parameters and the modified FIORIT risk indices (Fig 4B) highlighted that the RLC did not alter the direction or significance of the previously observed trend, though it did impact on the explained variance of the two microbial parameters. (Table 5)..

\section{Extending FIORIT for the Taw Catchment Case Study}

The statistically significant relationship between microbial water quality parameters and FIORIT risk indices was used to extend the application of FIORIT to a larger cross sample of fields to gauge the variability in field-scale risk of FIO delivery to water at the farm scale. The output of 
FIORIT is summarised as a frequency distribution of results from the seasonal assessment of 162 grassland fields across 10 farms in the Taw Catchment, Devon (Fig 5). The data presented in Fig. 5 are based on field assessment, GIS data and collected management information. Of the surveyed fields, the majority fell within the negligible and low risk category $(88 \%, 87 \%, 85 \%$ and $90 \%$ for winter, spring, summer and autumn, respectively). The seasons accommodating the highest proportion of 'very high' risk fields was found to be summer and autumn (both 1\%) whereas winter and spring were ranked as having no 'very high' seasonal risk. When FIORIT was modified to include the RLC these distributions shifted slightly so that proportions of the medium to high risk fields were reduced (Fig 5).

\section{DISCUSSION}

Development of practical and pragmatic approaches to mitigating microbial pollution from agriculture at the farm level requires identification of: (i) CSAs of FIO loss; (ii) reasons why CSAs exist; and (iii) management strategies to reduce risk. Clearly the importance of field sources depends on the timing and extent of faecal deposition and die-off rates (Vinten et al., 2008), and land application of manures in spatially and temporally heterogeneous patterns (Scholefield et al., 2007). While such FIO source burdens are clearly spatially and temporally complex, the study reported in this paper suggests that basic RFs, derived from field assessment, nationally available datasets and farm survey, can be coupled with current scientific understanding and supported by published research and professional judgement to offer an initial approximation of the relative risk of FIO loss from land to water without the need for quantitative risk assessment. The output of FIORIT can be complementary to other risk assessment management strategies. For example, in the UK Defra manure management and soil management plans (Defra, 2003; Defra, 2005a) which are linked to environmental stewardship schemes (Defra, 2005b), help raise awareness of manure spreading strategies and other farm activities that could potentially cause pollution of watercourses. Thus, the format represents a system which is familiar to farmers and landowners and this is likely to be advantageous for successful uptake or coupling of the tool with 
complementary management plans provided that a user-friendly interface is developed to facilitate integration of the different input data sources.

Undoubtedly, the conceptual framework of FIORIT is constrained by existing knowledge, but this has also been the case with the PI during development from its original conceptualization (Bechmann et al., 2007) and this applies to most models of diffuse pollution. We have demonstrated the potential for modification of FIORIT via inclusion of the RLC; but additionally, as our understanding and associated wealth of research findings grow, end-users can further adapt the tool to incorporate new knowledge, local factors and subsequent refinements. In the absence of conclusive field-scale evidence on the relative magnitudes of each RF, the elicited expert weightings provide a first-approximation and also hypotheses to be tested in the future but are, of course, subject to uncertainty as evidenced by Figure 3. However, the flexibility in tool structure serves to 'future-proof' FIORIT in a way that can facilitate adaptive modelling (Beven, 2007). As an example, die-off of FIOs is currently reflected within FIORIT via the 'aged faecal material' $\mathrm{RF}$, and also links to risks attributed to different livestock types related to a combination of factors such as volumes of faeces excreted and physical properties and release riskiness of the faeces rather than strict relationship with die-off, where there exists much uncertainty. Little research has actually been reported on field scale die-off of $E$. coli or IE in different types of livestock faeces through different months of deposition (Van Kessel et al., 2007). While FIORIT functions well enough using a simplistic surrogate for die-off without including seasonal die-off corrections relating to UV and temperature fluctuations, development of an established database of such information would provide the foundation to refine FIORIT to accommodate such inclusions in the future.

The higher stream flow associated with Farm B was partly responsible for the elevated FIO flux regularly recorded at this farm (Fig 2). However, management practices and inherent landscape features would clearly influence concentrations of cell export from land, and hence contribute to variations in fluxes recorded in receiving streams. For example, the differences in flux observed 
in Figure 2 during spring at Farm A and B relate not only to stream flow but also to differences in animal and manure application activity. Farm A received a single application of FYM in winter and spring and was not grazed until June, whereas Farm B received fresh faecal inputs from grazing sheep and lambs throughout March to May. The upward trends shown in Figure 4 are consistent with increasing influence of the FIO burden to land on microbial loads at monitoring sites (Lewis et al., 2005). This FIO burden was largely derived from grazing and stock movements, particularly as animals were turned out from winter housing. However, the intercept was higher than what we would expect. At lowest levels of risk, FIORIT indicated a stream flux of between 3-10 CFU mL $\mathrm{mL}^{-1} \mathrm{~s}^{-1}$, which is not consistent with negligible flux risk. This higher than expected intercept may be relate to: (1) the potential contribution of uncontrolled inputs derived from wild animals (Meays et al., 2006); (2) livestock access to watercourses that may re-suspend stream sediment which can contain historical FIO risk from past pollution events (Jamieson et al., 2005); and (3),annual rainfall for the south west of England in 2006 being only $1129 \mathrm{~mm}$ (Met Office, 2007), 7\% lower than the 1961-1990 long term average. Microbial data presented within this evaluation therefore represents the results from a particularly dry year during which storm flow events were scarce at the sampling sites. The FIORIT is used to identify potential risk of fields, but for potential risk to become an actual risk, rainfall is needed to act as a driving mechanism. We can speculate that had we obtained high flow event data, then the high risk indices may have been associated with microbial loads several orders of magnitude higher than those reported (McDonald and Kay, 1981; Kay et al., 2008b), thus increasing the slope of the relationship and reducing the intercept.. Similarly, the range of flux data for both farms would probably have been much larger if wet weather had predominated.

Interestingly, the results show slight differences (in terms of biological variability) between the two FIOs monitored and their relation with increasing risk indices. However, as would be expected, both follow the same upward trend. Such differences could be a reflection of their differential die-off patterns in various agricultural matrices (Wang et al., 2004). Others have shown that FC and IE exhibit significantly different release kinetics from manure sources and 
have suggested that FC may have resided in more liquid parts of manure, whereas IE were apparently present in less readily suspended, possibly solid, parts of manure (Guber et al., 2007); and this could also have contributed to differences in explained variance between the two organisms. So, the RLC derived indices are perhaps more reflective of runoff related risks and this may explain the strengthening of the IE relationship with the modified FIORIT risk indices in Figure 4B.

The frequency distribution data shown in Figure 5 is positive in that it highlighted that the majority of fields $(>85 \%)$ within our representative sample were deemed to be of negligible or low risk throughout the year (through either limited source or transfer potential within fields). This suggested that bacterial pollution was sourced from a small proportion of critical fields that facilitate the routing of faecal bacteria through the environment to surface waters. Similar findings, derived from nutrient management tools, have been reported for P (Coale et al., 2002) and others have documented that small agricultural areas $(<20 \%$ of catchment area) can be responsible for the majority of $\mathrm{P}$ pollution incidents (Heathwaite et al., 2000). While the highest risk fields make up only a small proportion of the total fields assessed, their ability to link high FIO source areas to watercourses makes them a particular concern and a priority for mitigation. Including a temporal component in FIORIT was important because different agricultural activities were typical of particular times of the year suggesting that an annual risk map would not be of an appropriate resolution to capture fluctuations in potential FIO loss from land to water. FIORIT provided a simple means of identifying potentially high risk periods of the year and spatial hotspots of FIO loss from land to water on working farms.

\section{Future Potential and lessons learned}

At present FIORIT remains prototypical in design, but its development has progressed following the protocols proposed by Jakeman et al. (2006) and Refsgaard et al. (2007) with respect to definition of tool purpose and associated modelling context, tool conceptualisation, rationale for parameter inclusion within the tool structure and preliminary evaluation and uncertainty analysis. 
This procedure, combined with model evaluation, has been well demonstrated for previous studies (Robson et al., 2008; Welsh, 2008). While we acknowledge uncertainties associated with expert weightings, we maintain that model uncertainty must be considered in the context of the purposes of the model (Jakeman et al., 2006). The FIORIT was designed to assist land-owners to make decisions based on relative risk rather than to quantitatively predict water quality impairment where discrepancies in observed and predicted data would be much more critical. The implicit uncertainties that were translated from the expert consultation exercise will instead help us frame priorities for future research. For example, the three RFs contributing the greatest error intrinsic to the risk index, namely cattle access to streams, overland flow distance and runoff potential should be a priority for future research. The highest uncertainty, linked to cattle access to streams, equates to a lack of knowledge with regard to how effective stream bank fencing would be in relation to improvements in microbial water quality. Uncertainty in overland flow accumulation and runoff potential highlights the lack of current understanding with regard to episodic runoff events and their role in providing connectivity from source to stream. Indeed, flow connectivity simulation has been advocated by others as a complementary modelling approach to pursue further (Kay et al., 2007).

Furthermore, by applying FIORIT to a case study catchment it has become clear that next steps should include the development of a user-interface for FIORIT so that end-users of this research tool are able to input associated data for farm environments in order to derive index output. This would require a coupling of standard GIS software with a database of risk indices and those datasets specified as pre-requisites for FIORIT. Additionally, scaling opportunities exist to account for within-field variability of risk which would offer higher resolution determination of critical source areas and provide a more targeted system of management or mitigation once high risk fields have been identified. Perhaps a more interesting use of FIORIT is to use it as a device to aid thinking and generate discussions within focus groups of scientists, land managers and farmers (c.f. Hewett et al., 2004). This would also allow for qualitative verification of the tool's capabilities with knowledgeable stakeholders and, should the tool function inappropriately for a 
given scenario, then the assumptions and weightings would need to be re-evaluated (Jakeman et al., 2006). Using FIORIT in this way would enable knowledge exchange, interactions and idea sharing between scientists and end-users but also ensure that the credibility of FIORIT would continue to evolve. In this respect FIORIT can therefore be used as a scenario testing tool, allowing changes in potential risk to be calculated based on changes in farm management.

We reiterate that fields ranking as negligible risk will still pose a small risk of FIO loss to watercourses via slower hydrological routes, but relative to other fields whereby visible and rapid overland flow pathways were connecting faecal sources directly to the watercourse, then a risk classification of 'negligible' remains appropriate. Critically, this does not mean that such fields can be over-burdened with manure applications because of being classified as negligible risk of contributing FIOs to water. The key point is that holistic strategies of risk assessment for other pollutants (e.g. P and N) should be employed so that FIORIT will be used in conjunction with recommended guidelines for manure application rates and stocking densities.

\section{CONCLUSIONS}

This evaluation has highlighted the potential for FIORIT to rank farm fields according to their relative risk of FIO contribution to watercourses. While preliminary analysis suggested that on average there is approximately $+/-30 \%$ error between the $50^{\text {th }}$ and the $25^{\text {th }}$ and $75^{\text {th }}$ percentiles of the FIORIT output this is a first approximation of an FIO risk indexing tool so future adaptation and modification must be encouraged and as with the PI, development will progress with the extension of our knowledge base.. We have purposely structured FIORIT so as not to overcomplicate the framework and to allow for a flexible and practical strategy for on-farm microbial vulnerability mapping. Indeed, complexity is not justified if all that is required is a general risk assessment framework for more specific, on farm advice (Strauss et al., 2007) and prioritization of mitigation strategies. However, the next phase is to test FIORIT in different geographical locations beyond the case study catchment and gather more on-farm data to facilitate the widening scope of the tool's capabilities (Scholten et al., 2007). Beyond this, further validation and 
modifications of the tool will help ensure FIORIT serves its intended purpose, both in the short term for framing research needs, as evidenced by the uncertainty in expert weighting, and in the long term through development into a robust indexing tool.

\section{ACKNOWLEDGEMENTS}

The authors would like to acknowledge the participation of the 16 anonymous experts for their valuable contributions in the risk factor weighting exercise and Nick Bulmer for his valuable support and assistance with field work and analysis. We are grateful to both farmers who kindly allowed access to their land and sampling points and cooperated with farm survey requirements. This work was funded as part of project RES-224-25-0086 by the Rural Economy and Land Use (RELU) programme who receive financial support from the Biotechnology and Biological Sciences Research Council (BBSRC), the Natural Environment Research Council (NERC), the Economic and Social Research Council (ESRC), the Department for Environment, Food and Rural Affairs (Defra) and the Scottish Office. Finally, the constructive comments of Tony Jakeman and three anonymous referees helped to significantly improve the quality of this manuscript.

\section{REFERENCES}

Abu-Ashour, J. and Lee, H. 2000. Transport of bacteria on sloping soil surfaces by runoff. Environmental Toxicology 15, 149-153.

Aitken, M. N. 2003. Impact of agricultural practices and river catchment characteristics on river and bathing water quality. Water Science and Technology 48, 217-224.

Anonymous. 2002. The Microbiology of Drinking Water Part 5 - A method for the isolation and enumeration of enterococci by membrane filtration. The Environment Agency, UK.

Bechmann, M. E., Stalnacke, P. and Kvaerno, S. H. 2007. Testing the Norweigan phosphorus index at the field and subcatchment scale. Agriculture Ecosystems and Environment 120, 117-128. 
Beven, K. 2007. Towards integrated models of everywhere: uncertainty, data and modelling as a learning process. Hydrology and Earth System Sciences 11, 460-467.

Beven, K and Binley, A. 1992. The future of distributed models - model calibration and uncertainty prediction. Hydrological Processes, 6, 279-298.

Bilotta, G. S., Brazier, R. E., and Haygarth, P. M. 2007. Processes affecting the transfer of sediment and colloids, with associated phosphorus, from intensively farmed grasslands: erosion. Hydrological Processes 21, 135-139.

Buczko, U. and Kuchenbuch, R. O. 2007. Phosphorus indices as risk assessment tools in the USA and Europe - a review. Journal of Plant Nutrition and Soil Science 170, 445-460.

CEC, 2000. Council of the European Communities. Council Directive 200/60/EC of the European Parliament and of the council of 23 October 2000 establishing a framework for community action in the field of water policy. Official Journal of European Union L327, $1-72$.

CEC, 2006. Council Directive 2006/7/EC of the European Parliament and of the council of $15^{\text {th }}$ February 2006 concerning the management of bathing water quality and repealing Directive 76/160/EEC. Official Journal of the European Union. L64, 37-51.

Chadwick, D. R., Fish, R. D., Oliver, D. M., Heathwaite, A. L., Hodgson, C. J. and Winter, M. 2008. Management of livestock and their manure to reduce the risk of microbial transfers to water - the case for an interdisciplinary approach. Trends in Food Science and Technology, 19 240-247.

Chambers, B. J., Nicholson, R. J., Smith, K., Pain, B. F., Cumby T. R., and Scotford, I. M. 2001. Managing Livestock Manures: Booklet 2 - Making better use of livestock manures on grassland. 24 pp. Defra, Noble House, Smith Square, London SW1P 3JR.

Coale, F. J., Sims, T., and Leytem, A. B. 2002. Accelerated deployment of an agricultural nutrient management tool: The Maryland phosphorus site index. Journal of Environmental Quality $31,1471-1476$.

Collins, R., Elliott, S. and Adams, R. 2005. Overland flow delivery of faecal bacteria to a headwater pastoral stream. Journal of Applied Microbiology 99, 126-132. 
Cornelissen, A. M. G., van den Berg, J., Koops, W. J. and Kaymak, U. 2003. Elicitation of expert knowledge for fuzzy evaluation of agricultural production systems. Agriculture Ecosystems and Environment 95, 1-18.

Crowther, J. Wyer, M. D., Bradford, M., Kay, D., Francis, C., A., and Knisel, W. G. 2003. Modelling faecal indicator concentrations in large rural catchments using land use and topographic data. Journal of Applied Microbiology. 94, 962-973.

CSWM, 2009 http://www.lec.lancs.ac.uk/cswm/foodchains/pd4.php. Viewed on 12th May 2009.

Cuttle, S. P., Macleod, C. J. A., Chadwick, D. R., Scholefield, D., Haygarth, P. M., Newell-Price, P., Harris, D., Shepard, M. A., Chambers, B. J. and Humphrey, R. 2007. An inventory of the methods to control diffuse water pollution from agriculture (DWPA). Defra ES0203, London.

Davies-Colley, R. J., Nagels, J. W., Smith, R. A., Young, R. G. and Phillips, C. J. 2004. Water quality impact of a dairy cow herd crossing a stream. New Zealand Journal of Marine and Freshwater Research 38, 569-576.

Defra 2003. Manure management plan: a step by step guide for farmers. Viewed on $30^{\text {th }}$ April 2009. Available online at:

http://www.defra.gov.uk/corporate/regulat/forms/agri_env/nvz/manureplan.pdf

Defra, 2005a. Producing a soil management plan for environmental stewardship. Viewed on $30^{\text {th }}$ April 2009. Available online at: http://www.defra.gov.uk/erdp/pdfs/es/guidance/es-soilmanagement-plan.pdf

Defra, 2005b. Entry Level Stewardship Handbook. Viewed on 30th April 2009. Available online at: http://www.defra.gov.uk/erdp/pdfs/es/els-handbook.pdf.

Fetter, C.W. 2001. Applied Hydrogeology. 4th ed. New Jersey: Prentice Hall. 598 p.

Ferguson, C. M., Croke, B., Ashbolt, N. J. and Deere, D. A. 2005. A deterministic model to quantify pathogen loads in drinking water catchments: pathogen budget for the Wingecarribee. Water Science and Technology 52, 191-197 
Ferguson, C. M., Croke, B. F. W., Beatson, P. J., Ashbolt, N. J. and Deere, D. A. 2007.

Development of a process-based model to predict pathogen budgets for the Sydney drinking water catchment. Journal of Water and Health 5, 187-208.

Fish, R. D., Winter, M., Oliver, D. M., Chadwick, D. R., Selfa, T., Heathwaite, A. L. and Hodgson, C. J. 2009. Unruly pathogens: eliciting values for environmental risk in the context of heterogeneous expert knowledge. Environmental Science and Policy, in press

Goss, M and Richards, C. 2008. Development of a risk-based index for source water protection planning, which supports the reduction of pathogens from agricultural activity entering water resources. Journal of Environmental Management 87, 623-632.

Guber, A. K., Karns, J. S., Pachepsky, Y. A., Sadeghi, A. M., Van Kessel, J. S., and Dao, T. H. 2007. Comparison of release and transport of manure-borne Escherichia coli and enterococci under grass buffer conditions. Letters in Applied Microbiology 44, 161-167.

Heathwaite, A. L., Sharpley, A., and Gburek, W. 2000. A conceptual approach for integrating phosphorus and nitrogen management at watershed scales. Journal of Environmental Quality, 29 158-166.

Hewett, C. J. M., Quinn, P. F., Whitehead, P. G., Heathwaite, A. L., and Flynn, N. J. 2004. Towards a nutrient export risk matrix approach to managing agricultural pollution at source. Hydrology and Earth System Sciences 8, 834-845.

Hutchison, M. L., Walters, L. D., Moore, A., Crookes, K. M., and Avery, S. M. 2004. Effect of length of time before incorporation on survival of pathogenic bacteria present in livestock wastes applied to agricultural soil. Applied and Environmental Microbiology 70, 51115118.

Jakeman, A. J., Letcher, R. A. and Norton, J. P. 2006. Ten iterative steps in development and evaluation of environmental models. Environmental Modelling and Software 21, 602614.

Jamieson, R. C., Joy, D. M., Lee, H., Kostaschuk, R., and Gordon, R. J. 2005. Resuspension of sediment-associated Escherichia coli in a natural stream. Journal of Environmental Quality, 34 581-589. 
Jarvie, H. P., Haygarth, P. M., Neal, C., Butler, P., Smith, B., Naden, P. S., Joynes, A., Neal, M., Wickham, H., Armstrong, L., Harman, S., Palmer-Felgate, E. J. 2008. Stream water chemistry and quality along an upland-lowland rural land-use continuum, south west England. Journal of Hydrology, 350, 215-231.

Joy, D. M., Lee, H., Reaume, C. M., Whiteley, H. R. and Zelin, S. 1998. Microbial contamination of subsurface tile drainage water from field applications of liquid manure. Canadian Agricultural Engineering 40, 153-160.

Kay, D., Crowther J., Stapleton, C. M., Wyer, M. D., Fewtrell, L., Anthony, S., Bradford, M., Edwards, A., Francis, C. A., Hopkins, M., Kay, C., McDonald, A. T., Watkins, J. and Wilkinson, J. 2008a. Faecal indicator organism concentrations and catchment export coefficients in the UK. Water Research, 42, 2649-2661.

Kay, D., Crowther, J., Fewtrell, L., Francis, C. A., Hopkins, M., Kay, C., McDonald, A. T., Stapleton, C. M., Watkins, J., Wyer, M. D. 2008b. Quantification and control of microbial pollution from agriculture: a new policy challenge? Environmental Science \& Policy 11, 171-184.

Kay, D., Edwards, A. C., Ferrier, R. C., Francis, C., Kay, C., Rushby, L., Watkins, J., McDonald, A. T., Wyer, M., Crowther, J., and Wilkinson, J. 2007. Catchment microbial dynamics: the emergence of a research agenda. Progress in Physical Geography 31, 59-76.

Kress, M and Gifford, G. F. 1984. Fecal coliform release from cattle fecal deposits. Water Resources Bulletin 20, 61-66.

Lemunyon, J. L. and Gilbert, R. G. 1993. The concept and need for a phosphorus assessment tool. Journal of Production Agriculture 6, 483-486.

Lewis, D. J., Atwill, E. R., Lennox, M. S., Hou, L., Karle, B., and Tate, K. W. 2005. Linking onfarm dairy management practices to storm flow faecal coliform loading for California coastal watersheds. Environmental Modelling and Assessment 107, 407-425.

McDonald, A., and Kay, D. 1981. Enteric bacterial concentrations in reservoir feeder streams: baseflow characteristics and response to hydrograph events. Water Research 15, 961-968. 
McDowell, R. W. 2006. Contaminant losses in overland flow from cattle, deer and sheep dung. Water Air and Soil Pollution. 174, 211-222.

McDowell, R. W.,Drewry, J. J., Muirhead, R. W. and Paton, R. J. 2005. Restricting the grazing time of cattle to decrease phosphorus, sediment and E. coli losses in overland flow from cropland. Australian Journal of Soil Research 43, 61-66.

McLeod, M., Aislabie, J., Ryburn, J., McGill, A. 2008. Regionalizing potential for microbial bypass flow through new Zealand Soils. Journal of Environmental Quality, 37, 19591967.

Meays C. L., Broersma, K., Nordin, R., Mazumder, A., and Samadpour, M. 2006. Spatial and annual variability in concentrations and sources of Escherichia coli in multiple watersheds. Environmental Science and Technology 40, 5289-5296.

Morris, D. G. 1999. Sub-set of UK time-series of monthly rainfall grids. NERC, Institute of Hydrology, Wallingford.

Muirhead, R. W. 2009. Soil and faecal material reservoirs of Escherichia coli in a grazed pasture. New Zealand Journal of Agricultural Research, 52, 1-8.

Muirhead, R. W., Collins, R. P., and Bremer, P. J. 2006. Interaction of Escherichia coli and soil particles in runoff. Applied and Environmental Microbiology 72, 3406-3411.

Nguyen, M. L., Sheath, G. W., Smith, C. M., and Cooper, A. B. 1998. Impact of cattle treading on hill land 2. Soil physical properties and contaminant runoff. New Zealand Journal of Agricultural Research 41, 279-290.

Oliver, D. M., Heathwaite, A. L., Haygarth, P. M., and Clegg, C. D. 2005a. Transfer of Escherichia coli to water from drained and undrained grassland after grazing. Journal Environmental Quality 34, 918-925.

Oliver, D. M., Clegg, C. D., Haygarth, P. M., and Heathwaite, A. L. 2005b. Assessing the potential for pathogen transfer from grassland soils to surface waters. Advances in Agronomy 85, 125-180. 
Oliver, D. M., Haygarth, P. M., Clegg, C. D., and Heathwaite, A. L. 2006. Differential E. coli dieoff patterns associated with agricultural matrices. Environmental Science and Technology $40,5710-5716$.

Oliver, D. M., Clegg, C. D., Heathwaite, A. L. and Haygarth, P. M. 2007. Preferential attachment of Escherichia coli to different particle size fractions of an agricultural grassland soil. Water Air and Soil Pollution, 185, 369-375.

Pachepsky, Y.A., Sadeghi, A. M., Bradford, S. A., Shelton, D. R., Guber, A. K. and Dao, T. 2006. Transport and fate of manure-borne pathogens: Modeling perspective. Agricultural Water Management 86, 81-92

Preedy, N., McTiernan, K., Matthews, R., Heathwaite, L., and Haygarth, P. 2001. Rapid incidental phosphorus transfers from grassland. Journal of Environmental Quality 30, 2105-2112.

Quinton, J. N. and Catt, J. A. 2004. The effects of minimal tillage and contour cultivation on surface runoff, soil loss and crop yield in the long-term Woburn Erosion Reference Experiment on sandy soil at Woburn, England. Soil Use and Management 20, 343-349.

Refsgaard, J. C., van der Sluijs, J. P., Hoberg, A. L., and Vanrolleghem, P. A. 2007. Uncertainty in the environmental modelling process - a framework and guidance. Environmental Modelling and Software 22, 1543-1556.

Robson, B. J., Hamilton, D. P., Webster, I. T., and Chan, T. 2008. Ten steps applied to development and evaluation of process-based biogeochemical models of estuaries. Environmental Modelling and Software, 23, 369-384.

Scholefield, D., Jewkes, E and Bol, R. 2007. Nutrient cycling budgets in managed pastures. Soil Biology 10 215-255.

Scholten, H., Kassahun, A., Refsgaard, J. C., Kargas, T., Gavardinas, C. and Beulens, A. J. M. 2007. A methodology to support multidisciplinary model-based water management. Environmental Modelling and Software 22, 743-759.

Simsek, Z. and Veiga, I. F. 2000. The electronic survey technique: an integration and assessment. Organisational Research Methods 3, 93-115. 
Sinclair, A., Hebb, D., Jamieson, R., Gordon, R., Benedict, K., Fuller, K., Stratton, G. W, and Madani, A. 2009. Growing season surface water loading of fecal indicator organisms within a rural watershed. Water Research, 43, 1199-1206.

Sinton, L. W., Braithwaite, R. R., Hall, C. H. and Mackenzie, M. L 2007. Survival of indicator and pathogenic bacteria in bovine feces on pasture. Applied and Environmental Microbiology 73, 7917-7925

Strauss, P., Leone, A., Ripa, M. N., Turpin, N., Lescot, J. M., and Laplana, R. 2007. Using critical source areas for targeting cost-effective best management practices to mitigate phosphorus and sediment transfer at the watershed scale. Soil Use and Managment. 23S1 144-153.

Unc, A. and Goss, M. J. 2006. Culturable Escherichia coli in soil mixed with two types of manure. Soil Science Society of America Journal 70, 763-769.

USDA-NRCS. 1999. Soil Taxonomy. A basic system of soil classification fro making and interpreting soil surveys. Ag Handbook 436. Washington DC. 869pp.

U.S. EPA. 2009. National Summary of Impaired Waters and TMDL Information. U.S. Environmental Protection Agency, Washington, D.C. Available at: http://iaspub.epa.gov/waters10/attains_nation_cy.control?p_report_type=T. Accessed April 30, 2009.

Van Kessel, J. S., Pachepsky, Y. A., Shelton, D. R., and Karns, J. S. 2007. Survival of Escherichia coli in cowpats in pasture and in laboratory conditions. Journal of Applied Microbiology 103, 1122-1127.

Vinten, A. J. A., Sym, G., Avdic, K., Crawford, C., Duncan, A. and Merrilees, D. W. 2008.

Faecal indicator pollution from a dairy farm in Ayreshire, Scotland: source apportionment, risk assessment and potential of mitigation measures. Water Research 42, 997-1012.

VSN International. 2006. Genstat 9.1. 9th Edi. VSN Int., Hemel Hempstead, UK.

Wang, L., Mankin, K. R., and Marchin, G. L. 2004. Survival of faecal bacteria in dairy cow manure. Transactions of the ASAE 47, 1239-1246. 
Welsh, W. D. 2008. Water balance modelling in Bowen, Queensland, and the ten iterative steps in model development and evaluation. Environmental Modelling and Software 23, 195-205.

White, S. L., Sheffield, R. E., Washburn, S. P., King, L. D., and Green, J. T. 2001. Spatial and time distribution of dairy cattle excreta in an intensive pasture system. Journal of Environmental Quality 30, 2180-2187.

Wilkinson, J., Kay, D., Wyer, M. and Jenkins, A. 2006. Processes driving the episodic flux of faecal indicator organisms in streams impacting on recreational and shellfish harvesting waters. Water Research 40, 153-161.

\section{Figure captions}

Fig 1: Boundary maps of Fields 1 and 2 showing $10 \mathrm{~m}$ contours, elevation and immediate surrounding farmland. The white solid line represents the stream, with the solid white triangle indicating stream flow direction. The solid white circles identify stream monitoring locations (circle with superscript 2 denotes upstream monitoring site on Farm B). (C) Crown Copyright / database right 2007. An Ordnance Survey / EDINA supplied service).

Fig 2: 'Spring' time-series representation of faecal indicator organism (FC and IE) flux measurements and daily rainfall on Farm A and B (Chart A and B, respectively).

Fig 3: Preliminary uncertainty analysis of FIORIT risk indices for Fields 1 and 2 throughout all seasons of investigation where the boxes show the $25^{\text {th }}, 50^{\text {th }}$ and $75^{\text {th }}$ percentiles and the whiskers the $5^{\text {th }}$ and $95^{\text {th }}$ percentiles

Fig 4: A) Relationship between FIORIT risk indices of contributing fields and calculated seasonal average faecal coliform and intestinal enterococci flux at farm sampling sites B) Relationship between FIORIT risk indices of contributing fields modified using rainfall-likelihood coefficient (RLC) and calculated seasonal average faecal coliform and intestinal enterococci flux at farm sampling sites. Error bars represent 1standard error of logarithmic mean. CFU, colony forming unit.

Fig 5: Frequency distribution of FIORIT risk indices for 162 grassland fields across 10 representative farms. Black profile depicts original FIORIT indices; gray profile [V2] (and associated \% in parentheses) depicts FIORIT output corrected using a rainfall-likelihood coefficient. 


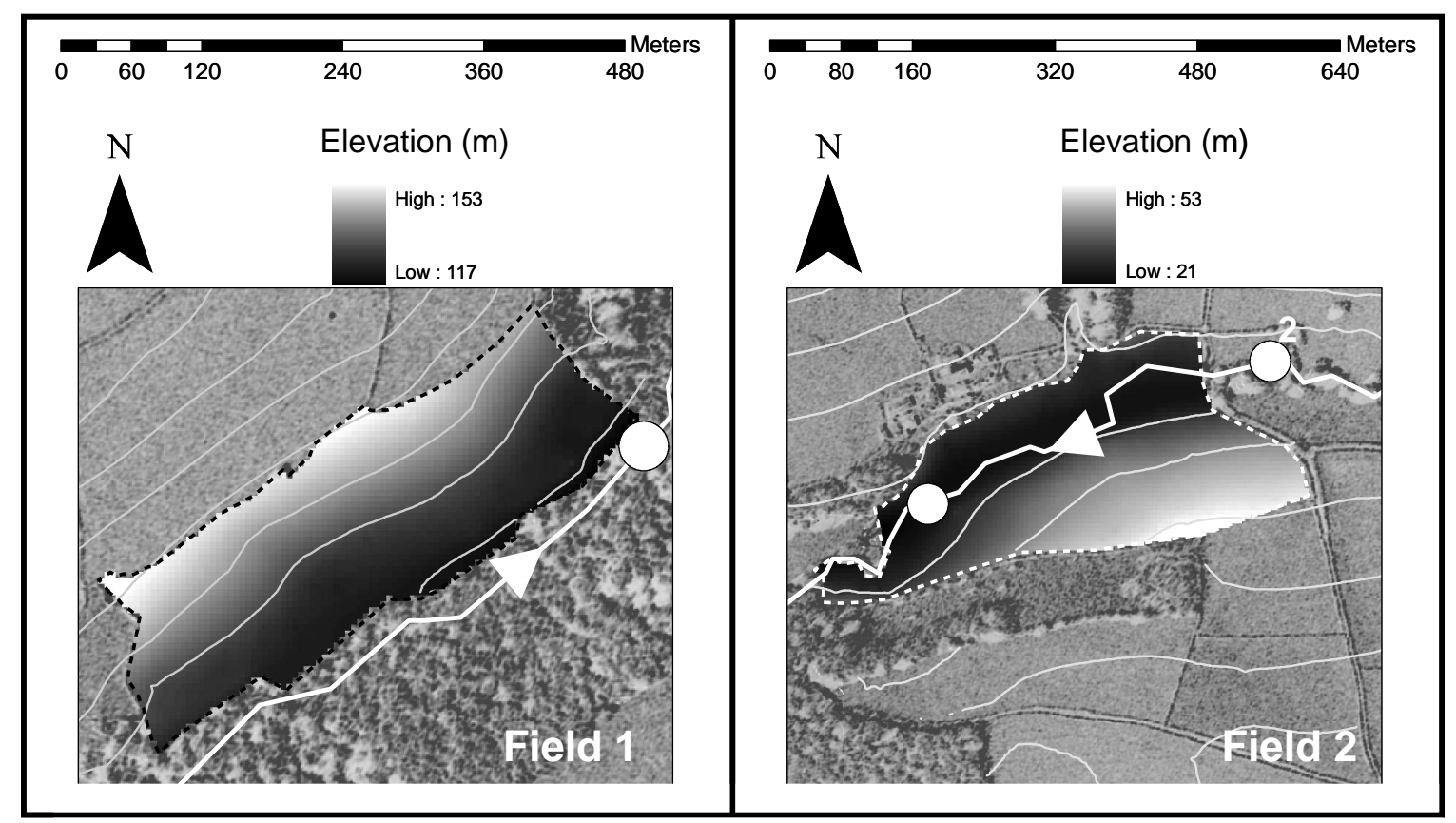

Fig. 1: Oliver et al. A risk indexing framework to evaluate the relative risk of fields contributing faecal bacteria to water 

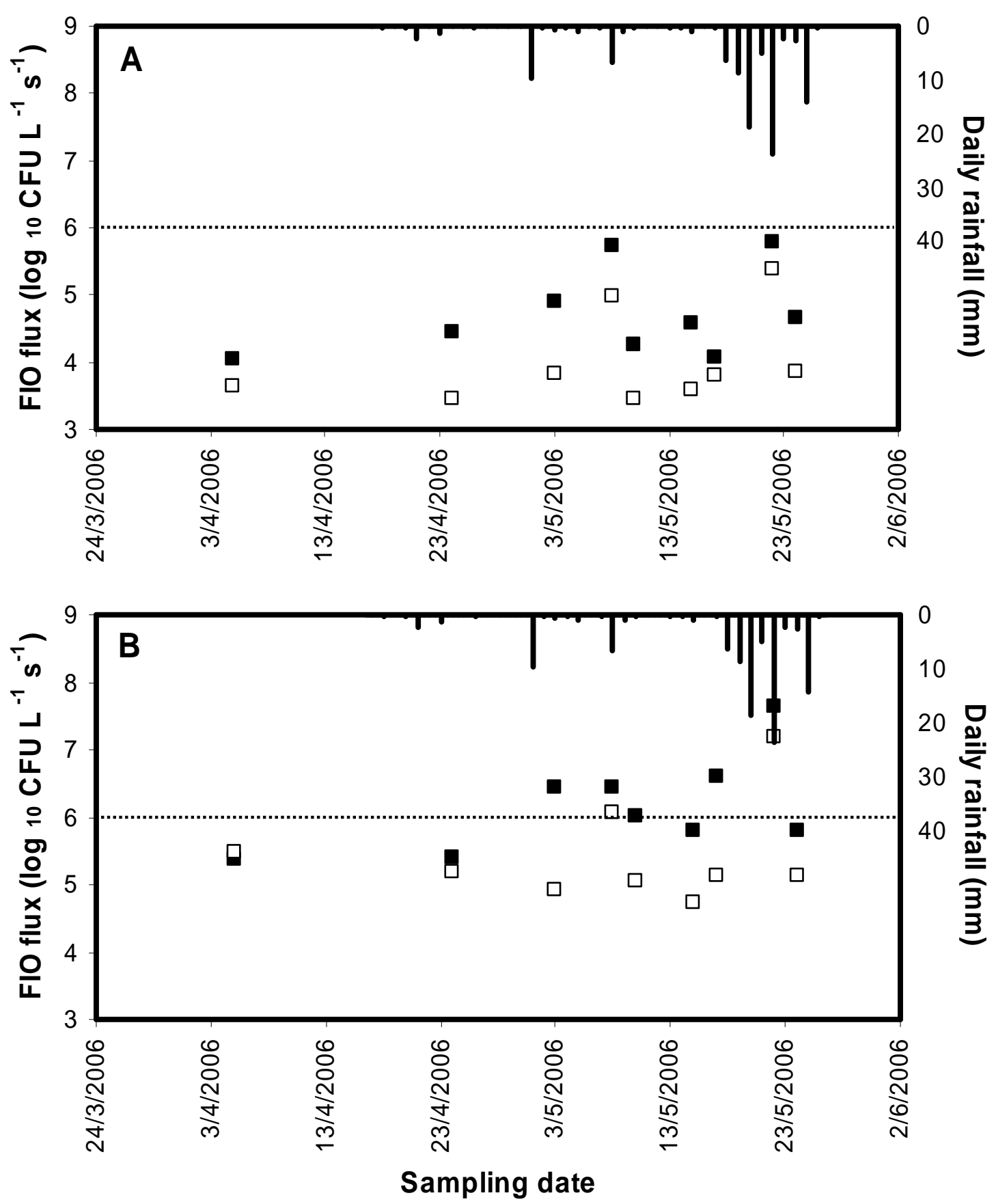

Faecal coliform $\square$ Intestinal enterococci Daily rainfall

Figure 2:

Oliver et al. A risk indexing framework to evaluate the relative risk of fields contributing faecal bacteria to water 


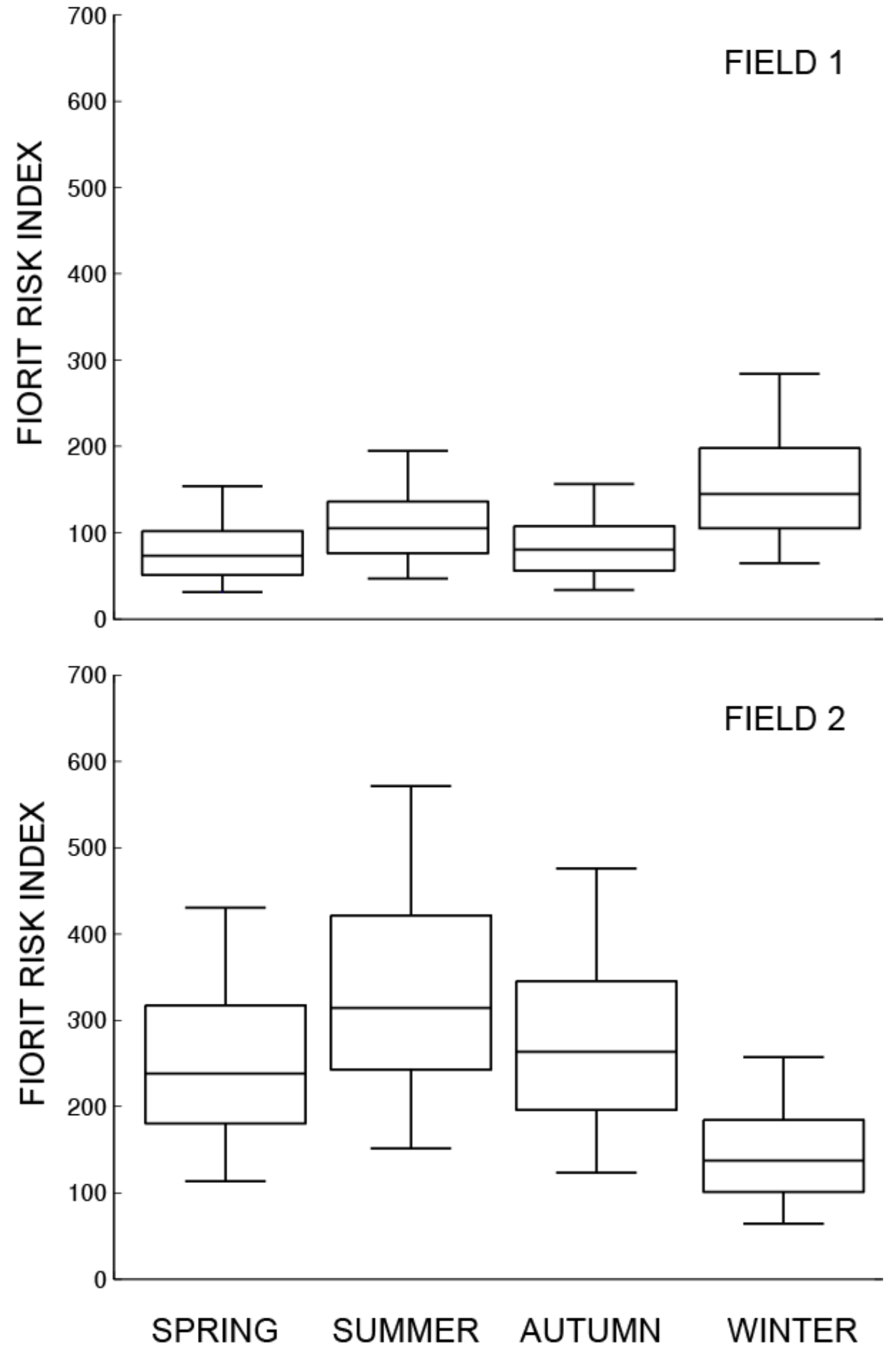

Figure 3:

Oliver et al. A risk indexing framework to evaluate the relative risk of fields contributing faecal bacteria to water 

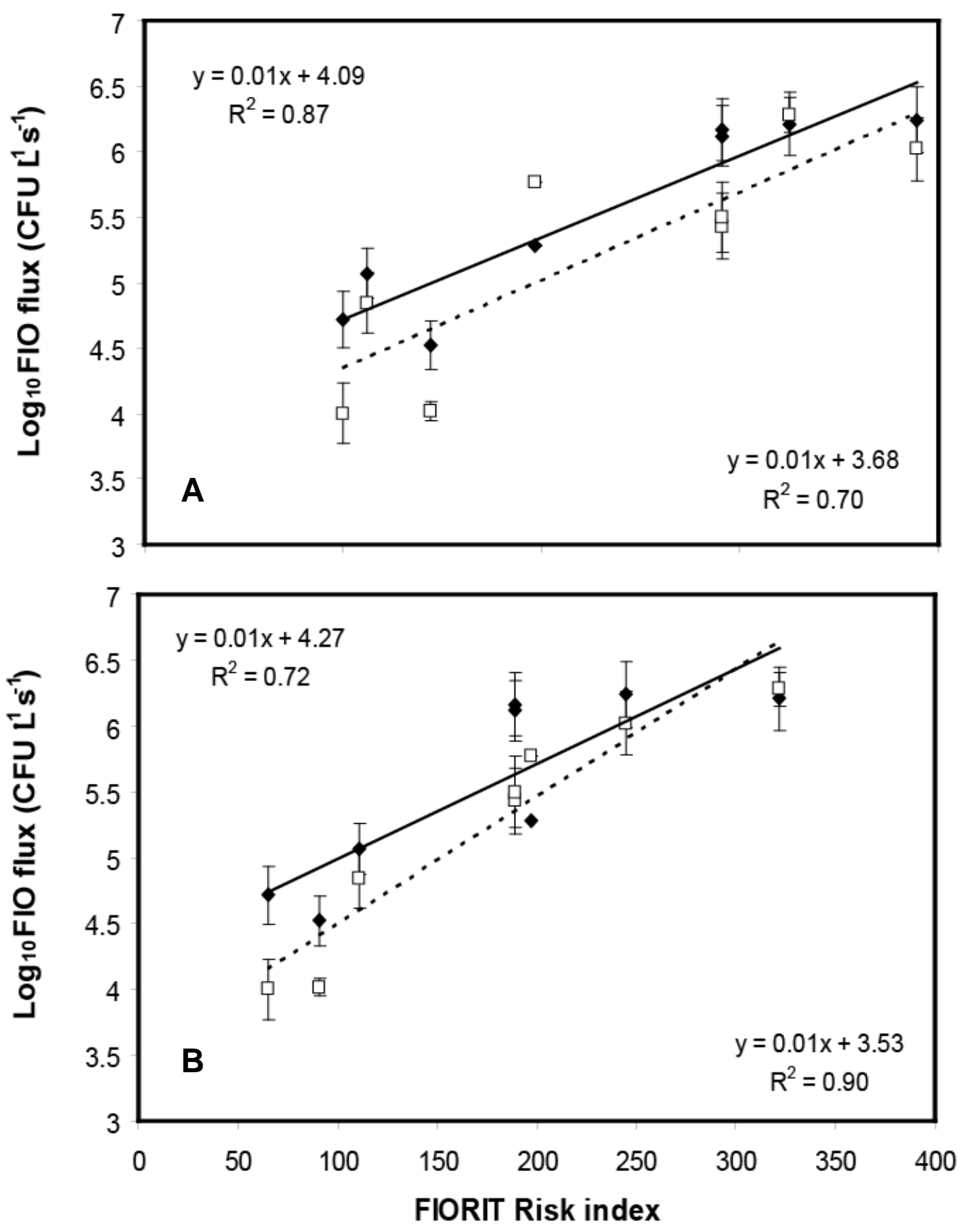

- Faecal coliform

- Intestinal enterococci

Linear (Faecal coliform)

.... Linear (Intestinal enterococci)

Figure 4:

Oliver et al. A risk indexing framework to evaluate the relative risk of fields contributing faecal bacteria to water 

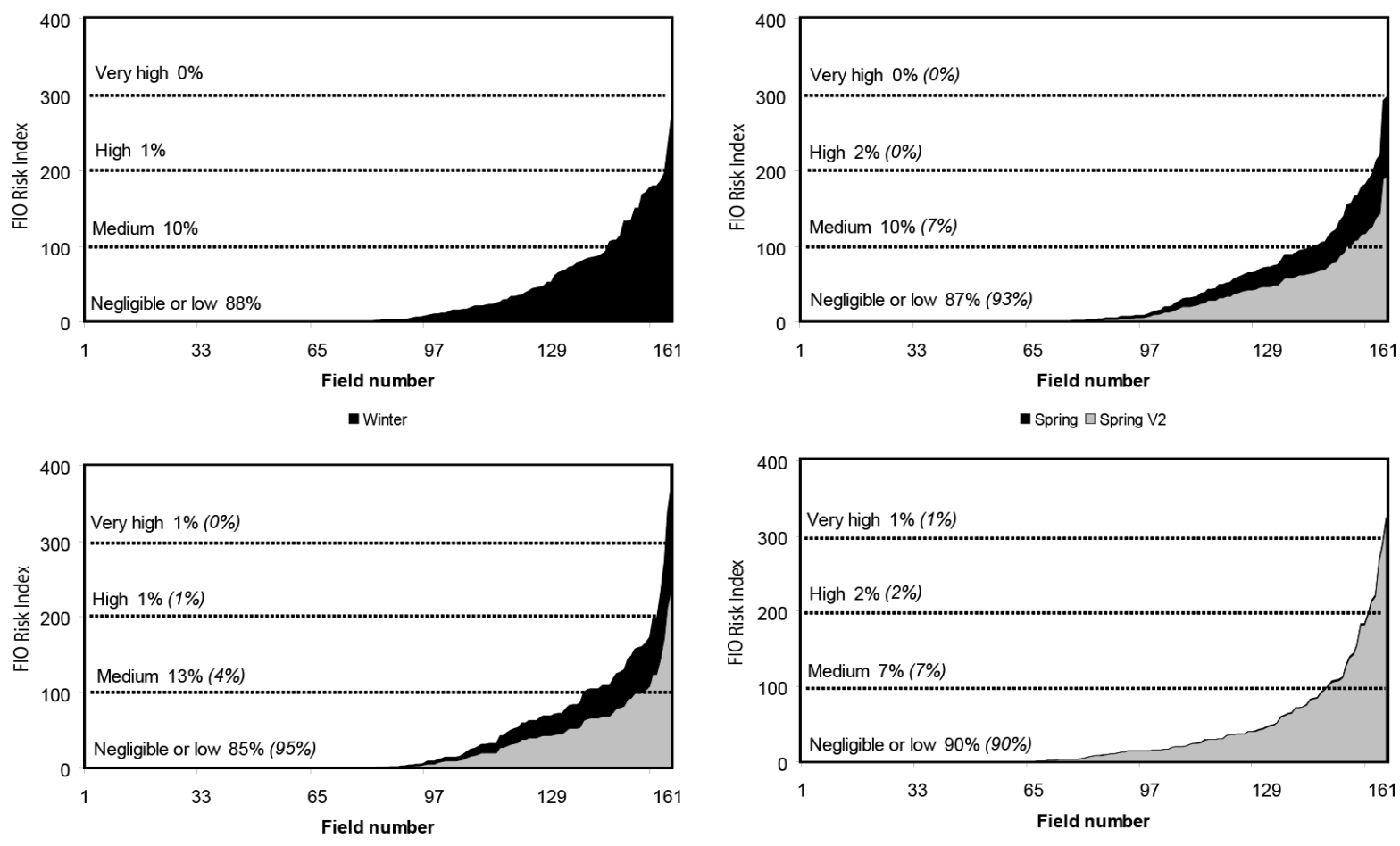

- Summer $\square$ Summer V2

- Autumn $\square$ Autumn V2

3

4

Figure 5: Oliver et al. A risk indexing framework to evaluate the relative risk of fields contributing faecal bacteria to water 